\title{
Clinical control of asthma associates with measures of airway inflammation
}

\author{
Franke Volbeda, ${ }^{1,2}$ Martine Broekema, ${ }^{3}$ Monique E Lodewijk, ${ }^{3}$ Machteld N Hylkema, ${ }^{3}$ \\ Helen K Reddel, ${ }^{4}$ Wim Timens, ${ }^{3}$ Dirkje S Postma, ${ }^{1}$ Nick H T ten Hacken ${ }^{1}$
}

\begin{abstract}
- Additional supplementary files are published online only. To view these files please visit the journal online (http://dx. doi.org/10.1136/thoraxjnl2012-201861).

'Department of Pulmonology, University Medical Centre Groningen, Groningen and University of Groningen, The Netherlands

${ }^{2}$ Pulmonary Rehabilitation Centre Beatrixoord, University Medical Centre Groningen, Groningen and University of Groningen, The Netherlands ${ }^{3}$ Department of Pathology, Groningen Research Institute on Asthma and COPD (GRIAC) University Medical Centre Groningen and University of Groningen, Groningen, The Netherlands

${ }^{4}$ Woolcock Institute of Medical Research and University of Sydney, Sydney, Australia
\end{abstract}

\section{Correspondence to} N H T ten Hacken, Department of Pulmonology, UMCG, PO Box 30001, Groningen 9700 $\mathrm{RB}$, The Netherlands; n.h.t.ten.hacken@umcg.nl

Received 5 March 2012 Revised 2 August 2012 Accepted 9 September 2012 Published Online First 6 October 2012

\begin{abstract}
Background Control of asthma is the goal of asthma management worldwide. The Global Initiative for Asthma defined control by a composite measure of clinical findings and future risk but without using markers of airway inflammation, the hallmark of asthma. We investigated whether clinical asthma control reflects eosinophilic inflammation in a broad population.
\end{abstract}

Methods Control of asthma was assessed over a period of 4 weeks in 111 patients with asthma: 22 totally controlled, 47 well controlled and 42 uncontrolled. Lung function, quality of life, airway hyperresponsiveness to AMP, sputum and blood eosinophils, exhaled nitric oxide (NO) and bronchial biopsies were obtained.

Results The 69 subjects with controlled asthma (totally and well controlled combined) had lower median blood eosinophil numbers, slope of AMP hyperresponsiveness, and alveolar NO levels than the 42 subjects with uncontrolled asthma: 0.18 (range $0.01-0.54$ ) versus 0.22 $(0.06-1.16) \times 10^{9} /$ litre $(p<0.05), 3.8(-0.4-17750)$ versus $39.7(0.4-28000) \mathrm{mg} / \mathrm{ml}(\mathrm{p}<0.05)$ and $5.3(1.5-14.9)$ versus $6.7(2.6-51.7) \mathrm{ppb}(p<0.05)$ respectively. Biopsies from subjects with controlled asthma contained fewer eosinophilic granules and more intact epithelium than uncontrolled subjects: $113(6-1787)$ versus $219(19-5313)$ $(p<0.05)$ and $11.8 \%(0-65.3)$ versus $5.6 \%(0-47.6)$ $(p<0.05)$ respectively. Controlled asthmatics had better Asthma Quality of Life Questionnaire scores than uncontrolled patients: 6.7 (5.0-7.0) versus 5.9 (3.7-7.0) $(p<0.001)$.

Conclusions The level of asthma control, based on a composite measure of clinical findings, is associated with inflammatory markers, particularly eosinophilic inflammation, with little difference between totally controlled and well controlled asthma.

\section{INTRODUCTION}

Aiming for total control of asthma by applying strict rules for treatment was the focus of the Gaining Optimal Asthma Control (GOAL) study in 2004. ${ }^{1}$ In this landmark study, totally controlled and well controlled asthma were composite measures based on respiratory symptoms during the day and night, use of rescue medication, peak expiratory flow (PEF) rate, exacerbations, emergency visits to the doctor or hospital, and adverse side effects of treatment. ${ }^{1}$ Indeed, many patients with uncontrolled asthma improved to a well controlled or totally controlled level after stepwise increase of fluticasone or fluticasone combined with salmeterol. In 2006 the Global Initiative for Asthma (GINA) ${ }^{2}$ emphasised the importance of

\section{Key messages}

- Control of asthma, based on a composite measure of clinical findings, is associated with direct and indirect markers of inflammation, particularly eosinophils.

- From the patients' perspective it is important to note that this composite measure is related to their quality of life.

- The relationship between clinical and inflammatory measures is not strong, indicating that inflammatory markers provide additional information about a patient's asthma status.

asthma control, and also defined it on the basis of a composite measure of clinical indices, with a later modification to include an assessment of the patient's future risk of adverse events. It was recognised that the clinical features of asthma could be well controlled in patients with mild, moderate or severe disease, as indicated by the level of treatment required. ${ }^{3}$ Surprisingly, a marker of inflammation was not included in the definition of asthma control, whereas chronic airway inflammation is the hallmark of asthma.

Airway inflammation does not correlate well with the level of lung function or symptoms of asthma. ${ }^{4}$ The question arises as to whether well or totally controlled asthma based on clinical criteria alone sufficiently reflects an adequate control of the underlying airway inflammation. Furthermore, while a patient may not perceive it as important to have minimal airway inflammation, optimal quality of life may be much more important..$^{5}$ Therefore, a more thorough insight is needed into the complex interplay between clinical control of asthma, quality of life and the underlying airway inflammation. Previous studies have focused on the relationship between asthma severity (defined at the time by symptoms and lung function) and eosinophilic inflammation. ${ }^{5-7}$ In this observational study we investigated multiple measures of eosinophilic airway inflammation and quality of life in subjects with totally controlled, well controlled and uncontrolled asthma, defined according to the strict GOAL criteria.

\section{METHODS \\ Subjects}

Smoking and non-smoking patients with asthma, aged 19-71 years, either using or not using inhaled 
corticosteroids (ICS), were recruited from research cohorts in Groningen, the Netherlands. All subjects had a past doctor's diagnosis of asthma and documented bronchial hyperresponsiveness to histamine (provocative concentration of histamine causing a $10 \%$ fall in forced expiratory volume in $1 \mathrm{~s}\left(\mathrm{FEV}_{1}\right)$ from baseline $\left(\mathrm{PC}_{10}\right.$ histamine $) \leq 16 \mathrm{mg} / \mathrm{ml}$, using $30 \mathrm{~s}$ tidal breathing). Moreover, patients were included if they had a provocative concentration of AMP causing a 20\% fall in $\mathrm{FEV}_{1}$ from baseline $\left(\mathrm{PC}_{20} \mathrm{AMP}\right) \leq 320 \mathrm{mg} / \mathrm{ml}$. If $\mathrm{PC}_{20} \mathrm{AMP}$ was higher, an additional histamine provocation challenge was performed within 2 weeks and subjects had to demonstrate a $\mathrm{PC}_{10}$ histamine $\leq 16 \mathrm{mg} / \mathrm{ml}$. The main exclusion criteria were: $\mathrm{FEV}_{1}<1.2$ litre, chronic obstructive pulmonary disease, bronchiectasis, upper respiratory tract infection (eg, colds) and/or use of antibiotics or oral corticosteroids within 2 months prior to inclusion in the study. The local medical ethics committee approved the study protocol and all subjects gave their written informed consent.

\section{Study design}

This prospective cross-sectional study involved subjects paying four visits to the clinic. At visit 1, written informed consent was obtained and patients were enrolled in the study if they fulfilled the inclusion criteria. Patients were instructed how to keep a diary and how to measure PEF at home for the next 4 weeks. At visit 2 (4 weeks later), clinical control of asthma was assessed from the diary according to the GOAL criteria (table E1 in online supplement) and quality of life was determined using the Asthma Quality of Life Questionnaire (AQLQ). ${ }^{8}$ Blood was drawn for measurement of eosinophils and atopy. Then reversibility of $\mathrm{FEV}_{1}$ was carried out with $800 \mu \mathrm{g}$ of inhaled albuterol (Ventolin) followed by sputum induction. Within 2 weeks, at visit 3, hyperresponsiveness to AMP was assessed. One to two weeks later this was followed by exhaled nitrogen monoxide (NO) measurements and a bronchoscopy (visit 4).

\section{Atopy}

The Phadiatop screening test was used to determine atopic status; it was performed on the ImmunoCap system, according to the manufacturer's instructions (Phadia AB, Uppsala, Sweden). The results are presented as quotients (fluorescence of the serum of interest divided by the fluorescence of a control serum). A positive Phadiatop was defined as patient serum/ control serum $>1$.

\section{Asthma quality of life}

The Dutch version of the AQLQ was used for this study. ${ }^{8}$ The AQLQ is scored on a seven-point scale, with 32 questions on four domains: symptoms, responses to environmental stimuli and the need to avoid them, limitation of activities and emotional dysfunction.

\section{Lung function}

$\mathrm{FEV}_{1}$ was measured with a calibrated water-sealed spirometer according to standardised guidelines. ${ }^{9}$ Reversibility of $\mathrm{FEV}_{1} \%$ predicted was measured with administration of $800 \mu \mathrm{g}$ of albuterol. Provocation tests were performed using a method adapted from Cockcroft et al. ${ }^{10}$ After initial nebulised normal saline, subjects inhaled doubling concentrations of AMP $(0.04-320 \mathrm{mg} / \mathrm{ml})$ by 2 min tidal breathing and at 5 min intervals. The slope of the AMP curve was calculated as the ratio between the change in $\mathrm{FEV}_{1}$ (difference between the value at baseline and at final dose of AMP) and the final dose of AMP. Bronchial hyperresponsiveness to histamine was tested as reported previously, ${ }^{11}$ using the
$30 \mathrm{~s}$ tidal breathing method and doubling concentrations ranging from 0.13 to $32 \mathrm{mg} / \mathrm{ml}$.

\section{Sputum induction and sputum processing}

Sputum was induced by inhalation of hypertonic saline aerosols as previously described. ${ }^{12}$ Hypertonic saline $(5 \%)$ was nebulised over three consecutive periods of $5 \mathrm{~min}$. Whole sputum samples were processed according to a method modified from that of Fahy et al. ${ }^{12}{ }^{13}$ May Grünwald Giemsa staining was used to obtain cell differentials from a total of 600 viable, nonsquamous cells. The sputum was not evaluated if the percentage of squamous cells was $>80 \%$ or if the total number of nonsquamous cells was $<600$.

\section{Alveolar and bronchial nitric oxide}

Exhaled NO (eNO) measurement was performed at multiple flow rates $(30,50,100$ and $200 \mathrm{ml} / \mathrm{s}$ ) on a NIOX (Aerocrine, Stockholm, Sweden). The mean eNO value (ppb) of three technically acceptable attempts per flow rate was used for analysis. The alveolar NO fraction (ppb) and the bronchial NO flux (nl/s) were calculated with a modification of the two-compartment model of NO exchange by Tsoukias and George. ${ }^{14} 15$

\section{Collection, processing, immunohistochemical staining and quantification of bronchial biopsies}

After local anaesthesia, bronchial biopsies were obtained using a flexible bronchoscope (Olympus BF P20 or BF XT20) from segmental divisions of the main bronchi. The biopsies were fixed in $4 \%$ formalin, processed and embedded in paraffin. Bronchial biopsies were cut into $3 \mu \mathrm{m}$ thick sections and stained with specific antibodies against a large panel of inflammatory markers. The inflammatory cells were quantified using computer-assisted image analysis (see Methods section in the online supplement for more details).

\section{Statistics}

All analyses were performed using SPSS V.14.0.1. The differences in the continuous variables between groups were tested with the Mann-Whitney U test for non-normally distributed data and with the independent sample $t$ test for normally distributed data. $\mathrm{PC}_{20}$ AMP, slope of AMP, blood, sputum and bronchial eosinophils, and eNO were transformed logarithmically to normalise their distribution. We compared the groups' dichotomous variables using the $\chi^{2}$ test and performed multiple logistic regression analysis to investigate which variables were significant determinants for asthma control.

\section{RESULTS}

\section{Patient characteristics}

One hundred and eleven patients with asthma with a median age of 50 years (range 19-71) were included (table 1). The reasons for not having totally controlled or well controlled asthma are given in the online supplement (table E1). Twenty-two subjects (20\%) were totally controlled, $47(42 \%)$ well controlled and 42 (38\%) uncontrolled.

\section{Markers of inflammation}

The 69 subjects with controlled asthma (totally and well controlled combined) had lower median blood eosinophil numbers than subjects with uncontrolled asthma: 0.18 (range 0.01-0.54) versus $0.22(0.06-1.16) \times 10^{9} /$ litre $\quad(p<0.05) \quad$ (figure 1$)$. The slope of $\mathrm{PC}_{20} \mathrm{AMP}$ was lower in patients with controlled asthma than in those with uncontrolled asthma: $3.8(-0.4-17750)$ versus $39.7(0.4-28000) \mathrm{mg} / \mathrm{ml}(\mathrm{p}<0.05)$. Alveolar NO levels 
Table 1 Baseline characteristics

\begin{tabular}{|c|c|c|c|}
\hline & \multicolumn{2}{|c|}{ Controlled asthma } & \multirow{2}{*}{$\begin{array}{l}\text { Uncontrolled } \\
\text { asthma }\end{array}$} \\
\hline & $\begin{array}{l}\text { Totally } \\
\text { controlled } \\
(n=22)\end{array}$ & $\begin{array}{l}\text { Well } \\
\text { controlled } \\
(n=47)\end{array}$ & \\
\hline Sex (men/women) & $10 / 12$ & $21 / 26$ & $22 / 20$ \\
\hline Age (years) & 48 (19-64) & $52(22-71)$ & $48(22-68)$ \\
\hline Atopy (Phadiatop ratio) & $4.93(0.13-96.5)$ & $5.56(0.06-106)$ & $27.3(0.15-128)^{*} \ddagger$ \\
\hline $\begin{array}{l}\text { Pack years in all } \\
\text { subjects }\end{array}$ & $0.9(0-31)$ & $2.0(0-64)$ & $0.2(0-45)$ \\
\hline Ex-smokers, n (\%) & $13(59)$ & $27(57)$ & $25(60)$ \\
\hline Current smokers, n (\%) & $7(32)$ & $12(26)$ & $10(24)$ \\
\hline $\begin{array}{l}\text { Cigarettes/day in } \\
\text { current smokers }\end{array}$ & $12.0(3-20)$ & $14.7(3-20)$ & $12.9(3-15)$ \\
\hline Ex-smokers, n (\%) & $13(59)$ & $27(57)$ & $25(60)$ \\
\hline $\begin{array}{l}\text { Pack years in all } \\
\text { subjects }\end{array}$ & $0.9(0-31)$ & $2.0(0-64)$ & $0.2(0-45)$ \\
\hline $\begin{array}{l}\text { Patients using ICS, } \\
\text { n (\%) }\end{array}$ & $5(23)$ & $26(55)$ & $30(71)^{* *}$ \\
\hline $\begin{array}{l}\text { Dose ( } \mu \text { g/day) in all } \\
\text { subjects } \Uparrow\end{array}$ & $0(0-1000) \S$ & $200(0-1200)$ & $450(0-1000)^{\star} \neq \ddagger$ \\
\hline $\begin{array}{l}\text { Dose ( } \mu \text { g/day) in } \\
\text { subjects using ICSI }\end{array}$ & $500(400-2000)$ & $\begin{array}{l}1000 \\
(200-2000)\end{array}$ & $800(100-2000)$ \\
\hline $\begin{array}{l}\text { Patients using LABA, } \\
\mathrm{n}(\%)\end{array}$ & $3(14)$ & $15(32)$ & $16(38)$ \\
\hline $\begin{array}{l}\text { Pre-bronchodilator } \\
\text { FEV }_{1} \text { (\% predicted) }\end{array}$ & $101(71-114) \S$ & $90(34-129)$ & $87(42-128) \ddagger^{*}$ \\
\hline $\begin{array}{l}\text { Pre-bronchodilator } \\
\mathrm{FEV}_{1} / \mathrm{FVC}(\%)\end{array}$ & $80(58-97) \S$ & 74 (39-88) & $73(40-97) \ddagger$ \\
\hline Reversibility FEV 1 (\%) & $8.7(0.7-23.9)$ & $9.0(1.5-23.3)$ & $\begin{array}{l}10.7 \\
(-2.2 \text { to } 38.4)\end{array}$ \\
\hline $\mathrm{PC}_{20} \mathrm{AMP}(\mathrm{mg} / \mathrm{ml})$ & $640(8.1-640)$ & $100(0.1-640)$ & $\begin{array}{l}7.7 \\
(0-640)^{* * *} † \neq \ddagger\end{array}$ \\
\hline \multicolumn{4}{|c|}{ 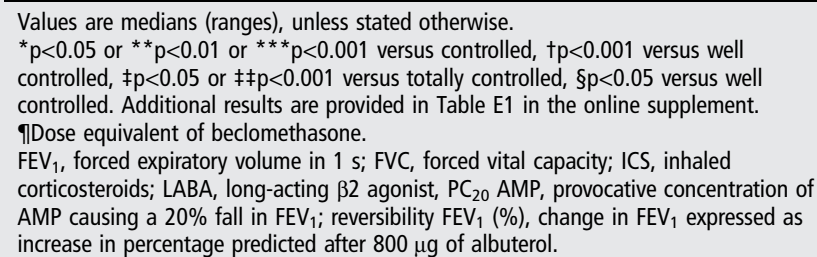 } \\
\hline
\end{tabular}

were lower in subjects with controlled asthma than with uncontrolled asthma: 5.3 (1.5-14.9) versus 6.7 (2.6-51.7) ppb $(\mathrm{p}<0.05)$ (Figure 1).

Sputum was evaluable in $72 \%$ of the subjects, which may have caused some bias to the results. The total number and proportion of inflammatory cell types did not differ significantly between controlled and uncontrolled subjects (table E2 in online supplement). Post hoc analysis in subgroups of patients with asthma divided according to current smoking status and current corticosteroid use did not affect these results. However, sputum eosinophils were less frequently outside the normal range of $>1.9 \%{ }^{16}$ in subjects with controlled asthma versus those with uncontrolled asthma: $9(19 \%)$ versus $13(39 \%)$ respectively $(\mathrm{p}<0.05)$. Using a cut-off point $>3 \%$ values were 7 $(16 \%)$ versus $12(36 \%)$ respectively $(p<0.05)$. Subjects with controlled asthma had a lower level of eosinophil activation than uncontrolled subjects, as determined by eosinophil peroxidase (EPX) immunopositivity in bronchial biopsies (table 2, figure 2). Controlled asthma was accompanied by an increase in intact epithelium compared with uncontrolled asthma (table 2, figure 2). All other inflammatory and remodelling variables we investigated were comparable in subjects with controlled and uncontrolled asthma (tables 2 and E3 in online supplement).

No differences were found in markers of inflammation between well controlled and totally controlled asthma. However, the slope of $\mathrm{PC}_{20}$ AMP tended to be higher in subjects with totally controlled asthma than in those with well controlled asthma $(\mathrm{p}=0.08)$ (figure 1$)$.

\section{Multiple logistic regression analysis on asthma control}

Multivariate logistic regression analysis was used to reveal which variables were independently associated with the level of clinical control. Due to multicolinearity all the variables related to eosinophilic inflammation could not be entered simultaneously into the model. We therefore created a model including sex, age, Phadiatop ratio, ICS use and $\mathrm{FEV}_{1} /$ vital capacity, in which we entered alveolar NO, blood eosinophils, AMP slope, EPX-positive pixels and the percentage intact epithelium separately. This showed that higher Phadiatop ratio and ICS use were significant determinants of worse asthma control in most of the models. It is noteworthy that a higher AMP slope (OR 0.39; 95\% CI 0.24 to 0.63 ) and higher EPX-positive pixel numbers (OR 0.32; 95\% CI 0.13 to 0.79 ) were significant determinants for worse asthma control (see Results section in online supplement).

\section{Comparison with asthma quality of life}

Subjects with controlled asthma demonstrated higher median scores in the total AQLQ than uncontrolled subjects: 6.7 (range $5.0-7.0)$ versus $5.9(3.7-7.0)(\mathrm{p}<0.001)$ (figure 3$)$. They also had significantly higher scores in all domains of the AQLQ: symptoms $6.7(4.9-7.0)$ versus $5.5 \quad(3.7-7.0)$, activity 6.8 (4.5-7.0) versus $6.3(3.9-7.0)$, emotion $7.0(5.0-7.0)$ versus 6.6 (3.8-7.0) and environment $6.5(3.8-7.0)$ versus 5.5 (3.0-7.0). AQLQ scores did not differ significantly between subjects with totally controlled and well controlled asthma.

\section{DISCUSSION}

The focus of the GINA ${ }^{2}$ shifted in 2006 from asthma severity before treatment to asthma control during treatment, with assessment based on a composite measure of clinical findings. There is now also considerable interest in controlling not only the clinical manifestations of asthma, but also the inflammatory and pathophysiological features of the disease. ${ }^{16}$ Although previous studies have described airway inflammation in patients classified by asthma severity, based on past severity classification systems, ${ }^{5-7}$ our study is the first to investigate whether the level of asthma control according to GOAL is associated with direct and indirect markers of airway inflammation. In a large group of patients with asthma with a wide spectrum of disease severity, patients with totally controlled and well controlled asthma demonstrated less hyperresponsiveness to AMP, lower NO levels in exhaled air, lower eosinophil numbers in peripheral blood, lower activated eosinophil numbers and more epithelial intactness in airway wall biopsies, and higher quality of life scores than subjects with uncontrolled asthma.

Our data suggest that good clinical control of asthma is associated with a lower degree of eosinophilic airway inflammation as assessed by indirect markers like $\mathrm{PC}_{20} \mathrm{AMP}$, eNO and peripheral blood eosinophils. Even more importantly, we found that good control of asthma was associated with less airway inflammation as seen by the classical biopsy findings of mucosal infiltration of activated eosinophils and better epithelial integrity. ${ }^{17}$ Thus, the concept of a composite measure for clinical asthma control, combining different variables like night-time and daytime symptoms, PEF, and use of rescue medication, appears 

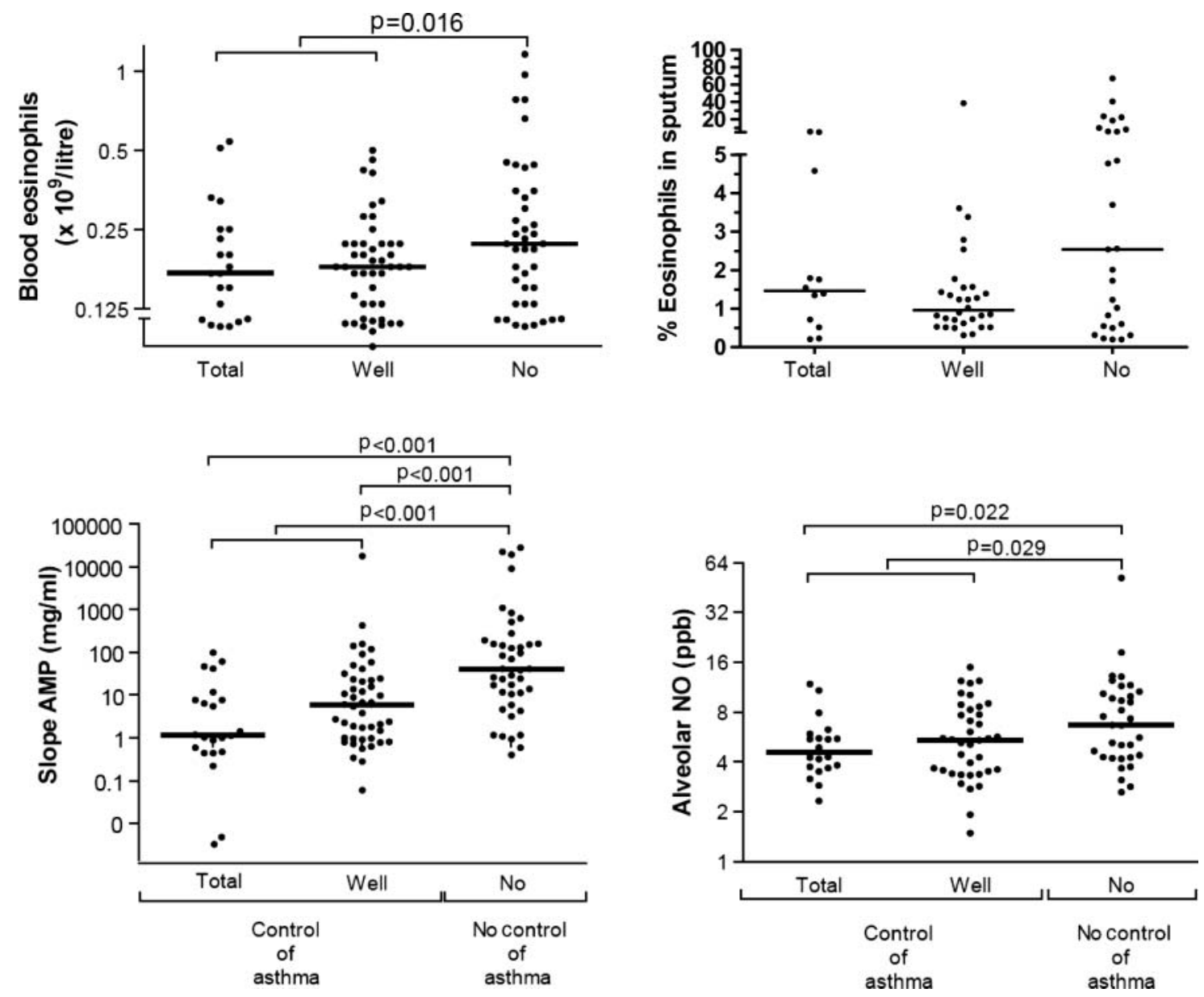

Figure 1 Biological parameters assessed in subjects with asthma. Peripheral blood eosinophils, sputum eosinophils (\%), slope of AMP and alveolar nitric oxide concentrations in patients with totally controlled, well controlled and uncontrolled asthma. Each dot represents one subject. Horizontal bars represent median values. No significant differences were found between totally controlled and well controlled asthma. NO, nitric monoxide.

to have an underlying pathobiological substrate. However, the associations between clinical control and eosinophilic inflammation were not strong, and no significant differences were seen in inflammation markers between totally controlled and well controlled subjects. The lack of correlation between clinical control and eosinophilic inflammation is consistent with emerging evidence for heterogeneity in inflammatory phenotypes, particularly in patients with non-corticosteroid responsive symptoms. ${ }^{18}$

We further demonstrate that different aspects of inflammation (NO, eosinophils, epithelial cells, $\mathrm{PC}_{20} \mathrm{AMP}$ ) stemming from different parts of the lung (exhaled air, blood, bronchial biopsies) are associated with good clinical control of asthma. This is not particularly surprising since all these inflammatory factors interact and contribute to the overall, general inflammation that is present in asthma. However, the heterogeneity of asthma with different inflammatory subtypes is increasingly acknowledged. ${ }^{18}{ }^{19}$ Our study also lends support to this concept, since less severe AMP hyperresponsiveness, lower eosinophil numbers and better epithelial integrity were all independently contributing to better asthma control. Regardless of the exact relationship, our results suggest that patients with better asthma control have less eosinophilic inflammation, although the relationship appeared weaker for sputum eosinophils than for biopsy or blood markers.

We had three unexpected findings in this study. First, the number of pack years smoking or the current smoking status did not contribute significantly to the level of asthma control,
Table 2 Inflammation and remodelling in biopsies

\begin{tabular}{|c|c|c|c|}
\hline & \multicolumn{2}{|c|}{ Controlled asthma } & \multirow{2}{*}{$\begin{array}{l}\text { Uncontrolled } \\
\text { asthma }\end{array}$} \\
\hline & $\begin{array}{l}\text { Totally } \\
\text { controlled } \\
(n=19)\end{array}$ & $\begin{array}{l}\text { Well } \\
\text { controlled } \\
(n=33)\end{array}$ & \\
\hline \multicolumn{4}{|l|}{ Inflammatory cells } \\
\hline Eosinophils & $2(0-26)$ & $1(0-21)$ & $2(0-32)$ \\
\hline Mast cells & $12(3-24)$ & $8(0-26)$ & $9(0-17)$ \\
\hline Macrophages & $15(0-30)$ & $12(0-47)$ & $11(0-57)$ \\
\hline Neutrophils & $9(0-46)$ & $5(0-34)$ & $6(0-20)$ \\
\hline T lymphocytes $\left(\mathrm{CD}^{+}\right)$ & $68(23-294)$ & 55 (13-177) & 66 (4-219) \\
\hline T lymphocytes $\left(C D 4^{+}\right)$ & $24(4-70)$ & $16(0-67)$ & $17(0-71)$ \\
\hline T lymphocytes $\left(\mathrm{CD}^{+}\right)$ & $25(4-139)$ & $17(0-136)$ & $23(1-205)$ \\
\hline \multicolumn{4}{|l|}{ Inflammatory cell activation } \\
\hline EPX immunopositivity & $157(16-1268)$ & $101(6-1787)$ & $219(19-5312)^{*}$, ** \\
\hline $\begin{array}{l}\text { Mast cell } \\
\text { degranulation (\%) }\end{array}$ & $80(22-100)$ & $69(25-100)$ & $75(0-100)$ \\
\hline \multicolumn{4}{|l|}{ Remodelling } \\
\hline BM thickness $(\mu \mathrm{m})$ & $6.3(4.3-9)$ & $5.2(3.6-8.7)$ & $5.9(2.8-12.6)$ \\
\hline Intact epithelium (\%) & $13(0-32.8)$ & $10.5(0-65.3)$ & $5.6(0-47.6)^{*}$ \\
\hline
\end{tabular}


Figure 2 Biopsy parameters assessed in subjects with asthma. Eosinophil peroxidase (EPX) immunopositivity (left panel) and the percentage of intact epithelium (right panel) in bronchial biopsies of patients with totally controlled, well controlled and uncontrolled asthma. Each dot represents one subject. Horizontal bars represent median values. No significant differences were found between totally controlled and well controlled asthma.

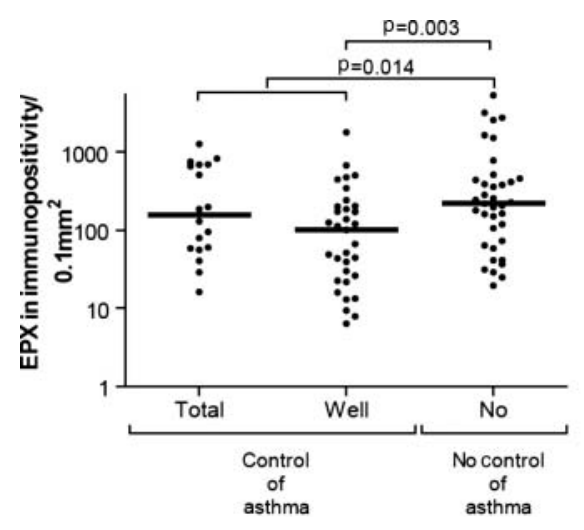

despite the fact that smoking has been associated with poorer asthma control in other studies. ${ }^{20-22}$ One explanation could be that the number of pack years smoking was low, just as the proportion of current smokers. Another explanation might be a 'healthy smoker' effect, that is, those with relatively healthy airways are able to tolerate smoke inhalation, to persist in their smoking habit while still showing good control of their asthma.

Second, ICS use contributed to the variation in asthma control, but in an opposite direction to that intuitively expected, that is, patients with uncontrolled asthma used ICS more frequently and with higher doses than patients with controlled asthma. This is likely to represent indication bias, in that patients with worse asthma control are more likely to be prescribed ICS. In addition, an 'unhealthy ICS' effect may have also been present in our study since it is known that some patients with asthma do not respond well to corticosteroids. ${ }^{23} 24$ This was also found in the GOAL study, in which $20-30 \%$ of the participants were still classified as having uncontrolled

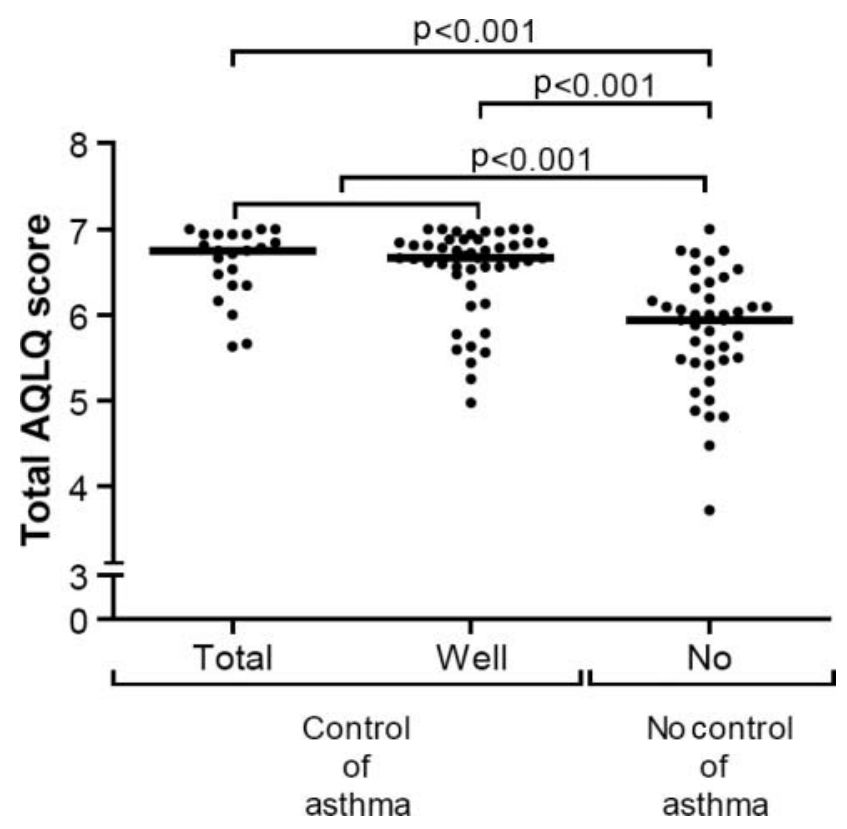

Figure 3 Asthma quality of life as assessed with the Asthma Quality of Life Questionnaire (AQLQ). The AQLQ (Juniper et $a^{8}{ }^{8}$ ) was given to subjects with totally controlled, well controlled and uncontrolled asthma. It is divided into four domains: symptoms, activities, emotions, environmental. Each dot represents one subject. Horizontal bars represent median values. No significant differences were found between totally controlled and well controlled asthma. asthma at the end of the study despite long-term administration of increasing doses of ICS.

Third, the level of asthma control by GOAL criteria did not significantly associate with lower sputum eosinophil levels, although significantly more patients with uncontrolled asthma had sputum eosinophils outside the normal range. ${ }^{16}$ Three previous studies, using a range of criteria for asthma control, have shown different results. Romagnoli et $a l^{25}(\mathrm{n}=35)$ found median sputum eosinophil levels of $0 \%$ and $2.5 \%(\mathrm{p}=0.01)$ in patients classified as having controlled and poorly controlled asthma, based on symptom frequency, night awakening, bronchodilator use and PEF variability. Quaedvlieg et $a l^{26}(\mathrm{n}=134)$ reported median sputum eosinophil levels of $0.4 \%, 1.4 \%$ and $5.6 \%(\mathrm{p}=0.001$ well controlled vs uncontrolled) for patients with asthma classified as well controlled, borderline and uncontrolled respectively by the six-item Asthma Control Questionnaire. ${ }^{27}$ In contrast, Shiota et $a l^{28}(\mathrm{n}=96)$ found no significant difference in sputum eosinophil levels for patients classified as having total, partial and uncontrolled asthma by the Asthma Control Test $^{29}(2.1 \%, 3.8 \%$ and $4.9 \%$ respectively, $\mathrm{p}=0.4)$. The differing eosinophil levels seen in these studies emphasise the potential variation due to patient selection. Unlike earlier studies, the present study also included eosinophilic markers in peripheral blood and airway wall biopsies, and these were found to better reflect a strict definition of asthma control. It is an intriguing finding that control of asthma significantly associates with lower peripheral blood eosinophils and lower activated eosinophil numbers in the bronchial wall, yet only weakly with sputum eosinophils. Nevertheless, across all three compartments, the findings demonstrate that assessment of airway inflammation provides additional information about asthma status than is obtained from clinical control measures.

The present study also confirms that health-related quality of life in patients with controlled asthma is significantly better than in uncontrolled asthma. As the difference between the two groups was higher than the minimal, clinically important difference of 0.5 point, this emphasises the overall impact of asthma control on health status. ${ }^{30}$ In addition, as in the GOAL study itself, $^{31}$ little difference was seen in absolute AQLQ scores between subjects with well controlled and totally controlled asthma, suggesting that further improvement in clinical asthma control may not be reflected in a clinically important difference in an individual's quality of life.

The participants in this study are not fully comparable to those in the larger GOAL study, ${ }^{1} 32$ which included only subjects with uncontrolled asthma with a smoking history of $<10$ pack years, whereas we also included subjects with totally controlled and well controlled asthma with no limit on smoking 
history. The GOAL study also included younger subjects (including children) and had a lower prevalence of ex-smokers, had lower lung function and higher bronchodilator reversibility. When comparing the reasons why patients failed to achieve total asthma control at baseline in the GOAL study ${ }^{32}$ and in our study (Table E1) there are a few striking differences. The percentages of patients failing to achieve total control due to the GOAL criteria were $63 \%$ due to awakening in GOAL versus $19 \%$ in our study, daytime symptoms $(95 \%$ vs $34 \%)$, rescue medication (92\% vs $26 \%$ ), and PEF $\geq 80 \%$ predicted $(72 \%$ vs $50 \%)$. Thus, the prevalence of daytime symptoms and rescue medication in the GOAL study were considerably higher than in our study. It is possible that the patients in the GOAL study had more severe disease because they also had a lower baseline lung function and more symptoms than our patients. Larger, explorative studies, also including patients with more severe asthma, will be needed to determine why some patients do not achieve total control of their asthma and this may have important consequences for the therapies prescribed.

In conclusion, our study demonstrates that clinical control of asthma is associated with direct and indirect markers of airway inflammation, but that airway inflammation provides different information about asthma status from that provided by clinical measures of control. Moreover, better asthma control associates with a higher quality of life for the patients. Although aiming for good clinical control of asthma, as recommended by the GINA guidelines, is important for suppressing the underlying airway inflammation and from a patient's perspective, the present findings do not support a routine increase in ICS treatment for patients with well controlled asthma. Longitudinal intervention studies are needed to assess if the control of asthma concept may recognise patients with asthma who are at higher future risk of exacerbations, accelerated decline in lung function and side effects of treatment.

Acknowledgements The authors would like to thank all the participants and the lung function department of Beatrixoord, Groningen for their help in collecting all the lung function and sputum data. We thank Dr J Vonk for help with the final statistical analysis and I Senior for critically reading the manuscript. We thank Dr J Lee and Dr N Lee (Mayo Clinic, Scottsdale, Arizona, USA) for providing the anti-EPX antibody.

Funding GlaxoSmithKline gave an unrestricted grant (SAM101761) to this investigator initiated study.

Contributors DSP, WT, MNH, and NHTtH were all involved in the design of the study, carrying-out the study, analysis of data, interpretation of results, and reviewing of the manuscript. FV recruited the patients and coordinated the patient-related investigations and organised a database. MEL performed all lab work, including the quantitate analysis of biopsies and sputum. MB was also involved in the quantitative analysis of biopsies and sputum; additionally she did the statistical analyses and wrote the first drafts of the manuscript together with NHTtH. HKR reviewed the manuscript and contributed to some major changes. FV and MB contributed equally.

Competing interests Professor Postma consulted to AstraZeneca, Boehringer Ingelheim, GSK, Nycomed and Teva, and received grants from GlaxoSmithKline, Chiesi, Nycomed and AstraZeneca. Dr ten Hacken received grants from Chiesi, GlaxoSmithKline, Nycomed, Boehringer Ingelheim. Dr Reddel has provided consulting for AstraZeneca and Novartis, is on a data monitoring committee for AstraZeneca, GlaxoSmithKline, Merck and Novartis, and has received grants from GlaxoSmithKline. The other authors have no competing interests.

Ethics approval Ethical Committee of the University Medical Center Groningen.

Provenance and peer review Not commissioned; externally peer reviewed.

\section{REFERENCES}

1 Bateman ED, Boushey HA, Bousquet J, et al. Can guideline-defined asthma control be achieved? The Gaining Optimal Asthma Control study. Am J Respir Crit Care Med 2004;170:836-44.
2 Global Initiative for Asthma (GINA). Global Strategy for Asthma Management and Prevention. 2006.

3 Taylor DR, Bateman ED, Boulet LP, et al. A new perspective on concepts of asthma severity and control. Eur Respir J 2008;32:545-54.

4 de Kluijver J, Evertse CE, Schrumpf JA, et al. Asymptomatic worsening of airway inflammation during low-dose allergen exposure in asthma: protection by inhaled steroids. Am J Respir Crit Care Med 2002;166:294-300.

5 Jenkins $C R$, Thien FC, Wheatley JR, et al. Traditional and patient-centred outcomes with three classes of asthma medication. Eur Respir J 2005;26:36-44.

6 Louis R, Lau LC, Bron AO, et al. The relationship between airways inflammation and asthma severity. Am J Respir Crit Care Med 2000;161:9-16.

7 Sont JK, Han J, van Krieken JM, et al. Relationship between the inflammatory infiltrate in bronchial biopsy specimens and clinical severity of asthma in patients treated with inhaled steroids. Thorax 1996:51:496-502.

8 Juniper EF, Buist AS, Cox FM, et al. Validation of a standardized version of the Asthma Quality of Life Questionnaire. Chest 1999;115:1265-70.

9 Miller MR, Hankinson J, Brusasco V, et al. Standardisation of spirometry. Eur Respir J 2005:26:319-38.

10 Cockcroft DW, Killian DN, Mellon JJ, et al. Bronchial reactivity to inhaled histamine: a method and clinical survey. Clin Allergy 1977;7:235-43.

11 Grol MH, Postma DS, Vonk JM, et al. Risk factors from childhood to adulthood for bronchial responsiveness at age 32-42 years. Am J Respir Crit Care Med 1999:160:150-6.

12 Meijer RJ, Kerstjens HA, Arends LR, et al. Effects of inhaled fluticasone and oral prednisolone on clinical and inflammatory parameters in patients with asthma 2. Thorax 1999;54:894-9.

13 Fahy JV, Liu J, Wong $\mathrm{H}$, et al. Cellular and biochemical analysis of induced sputum from asthmatic and from healthy subjects. Am Rev Respir Dis 1993;147:1126-31.

14 Rottier BL, Cohen van der J, et al. A different analysis applied to a mathematical model on output of exhaled nitric oxide. J Appl Physiol 2005;99:378-9.

15 Tsoukias NM, George SC. A two-compartment model of pulmonary nitric oxide exchange dynamics. J Appl Physiol 1998:85:653-66.

16 Reddel HK, Taylor DR, Bateman ED, et al. An official American Thoracic Society/ European Respiratory Society statement: asthma control and exacerbations: standardizing endpoints for clinical asthma trials and clinical practice. Am J Respir Crit Care Med 2009;180:59-99.

17 Beasley R, Burgess C, Crane J, et al. Pathology of asthma and its clinical implications. J Allergy Clin Immunol 1993;92(1 Pt 2):148-54.

18 Wenzel SE. Asthma: defining of the persistent adult phenotypes. Lancet 2006:368:804-13

19 Haldar P, Pavord ID, Shaw DE, et al. Cluster analysis and clinical asthma phenotypes. Am J Respir Crit Care Med 2008;178:218-24.

20 Chaudhuri R, McSharry C, McCoard A, et al. Role of symptoms and lung function in determining asthma control in smokers with asthma. Allergy 2008;63:132-5.

21 Pedersen SE, Bateman ED, Bousquet J, et al. Determinants of response to fluticasone propionate and salmeterol/fluticasone propionate combination in the Gaining Optimal Asthma Control study. J Allergy Clin Immunol 2007;120:1036-42.

22 Stanford RH, Gilsenan AW, Ziemiecki R, et al. Predictors of uncontrolled asthma in adult and pediatric patients: analysis of the Asthma Control Characteristics and Prevalence Survey Studies (ACCESS). J Asthma 2010:47:257-2.

23 Heaney LG, Robinson DS. Severe asthma treatment: need for characterising patients. Lancet 2005:365:974-6.

24 Dolan CM, Fraher KE, Bleecker ER, et al. Design and baseline characteristics of the epidemiology and natural history of asthma: Outcomes and Treatment Regimens (TENOR) study: a large cohort of patients with severe or difficult-to-treat asthma. Ann Allergy Asthma Immunol 2004;92:32-9.

25 Romagnoli M, Vachier I, Tarodo de la Fuente F, et al. Eosinophilic inflammation in sputum of poorly controlled asthmatics. Eur Respir J 2002;20:1370-77.

26 Quaedvlieg V, Sele J, Henket M, et al. Association between asthma control and bronchial hyperresponsiveness and airways inflammation: a cross-sectional study in daily practice. Clin Exp Allergy 2009;39:1822-29.

27 Juniper EF, Svensson K, Mork AC, et al. Measurement properties and interpretation of three shortened versions of the asthma control questionnaire. Respir Med 2005;99:553-8

28 Shiota N, Yokoyama A, Haruta Y, et al. Association of airway inflammation with asthma control level evaluated by the asthma control test. J Asthma 2011:48:907-13.

29 Nathan RA, Sorkness CA, Kosinski M, et al. Development of the asthma control test: a survey for assessing asthma control. J Allergy Clin Immunol 2004:113:59-65.

30 Juniper $E F$, Guyatt $\mathrm{GH}$, Willan $\mathrm{A}$, et al. Determining a minimal important change in a disease-specific Quality of Life Questionnaire. J Clin Epidemiol 1994;47:81-7.

31 Bateman ED, Bousquet J, Keech ML, et al. The correlation between asthma control and health status: the GOAL study. Eur Respir J 2007:29:56-62.

32 Bateman ED, Clark TJ, Frith L, et al. Rate of response of individual asthma control measures varies and may overestimate asthma control: an analysis of the goal study. J Asthma 2007:44:667-73. 